\title{
Diarylheptanoids from Alnus viridis ssp. viridis and Alnus glutinosa: Modulation of Quorum Sensing Activity in Pseudomonas aeruginosa
}

\author{
Authors \\ Tatjana Ilic-Tomic ${ }^{1}$, Marina Sokovic ${ }^{2}$, Sandra Vojnovic ${ }^{1}$, Ana Ciric ${ }^{2}$, Milan Veljic ${ }^{3}$, Jasmina Nikodinovic-Runic ${ }^{1}$, \\ Miroslav Novakovic ${ }^{4}$ \\ Affiliations \\ ${ }^{1}$ Institute of Molecular Genetics and Genetic Engineering, University of Belgrade, Belgrade, Serbia \\ 2 Institute for Biological Research "Sinisa Stankovic", University of Belgrade, Belgrade, Serbia \\ ${ }^{3}$ Faculty of Biology, University of Belgrade, Belgrade, Serbia \\ ${ }^{4}$ Institute of Chemistry, Technology and Metallurgy, University of Belgrade, Belgrade, Serbia
}

Key words

- Alnus viridis ssp. viridis

- Alnus glutinosa

- Betulaceae

- diarylheptanoids

- quorum sensing

- acyl homoserine lactone

- Pseudomonas aeruginosa

received October 6, 2015

revised March 26, 2016

accepted April 15, 2016

Bibliography

DOI http://dx.doi.org/

10.1055/s-0042-107674

Published online

Planta Med (c) Georg Thieme

Verlag KG Stuttgart · New York .

ISSN 0032-0943

\section{Correspondence \\ Dr. Miroslav Novakovic \\ Institute of Chemistry \\ Technology and Metallurgy \\ University of Belgrade \\ Studentski Trg 12-16 \\ 11000 Belgrade \\ Serbia \\ Phone: + 381112630474 \\ Fax: + 381112636061 \\ mironov76@yahoo.com}

Correspondence

Dr. Jasmina Nikodinovic-Runic Institute of Molecular Genetics and Genetic Engineering

University of Belgrade

Vojvode Stepe 444 a

11000 Belgrade

Serbia

Phone: + 381113976034

Fax: + 381113975808

jasmina.nikodinovic@

imgge.bg.ac.rs

\section{Abstract}

\section{$\nabla$}

Diarylheptanoids from the barks of Alnus viridis ssp. viridis (green alder) and Alnus glutinosa (black alder) were explored for anti-quorum sensing activity. Chemicals with anti-quorum sensing activity have recently been examined for antimicrobial applications. The anti-quorum sensing activity of the selected diarylheptanoids was determined using two biosensors, namely Pseudomonas aeruginosa PAO1 and Chromobacterium violaceum $\mathrm{CV} 026$. Although all of the investigated compounds negatively influenced the motility of $P$. aeruginosa PAO1, four were able to inhibit biofilm formation of this human opportunistic pathogen for $40-70 \%$. Three of the diarylheptanoids (3, 4, and 5) negatively influenced the biosynthesis of pyocyanin, which is under the control of quorum sensing. Platyphyllenone (7) and hirsutenone (5) were able to inhibit the biosynthesis of violacein in C. violaceum CV026, with 5 being able to inhibit the synthesis of both

\section{Introduction}

\section{$\nabla$}

Linear diarylheptanoids are secondary metabolites consisting of two benzene rings connected with a heptane skeleton ( $\bullet$ Fig. 1 ). The bestknown and most investigated member of this group is curcumin [1,2], a compound isolated from Curcuma longa L. (Zingiberaceae) almost 170 years ago, whose structure was determined in 1910 [3], but whose medicinal values were known for thousands of years [4]. Beside the genus Curcuma, diarylheptanoids are isolated from Zingiberaceae genera Zingiber and Alpinia, and Betulaceae genera Betula and Alnus. The first diarylheptanoids from Alnus species, yashabushiketol and dihydroyashabushiketol, were isolated from Alnus firma Siebold \& Zucc. in 1969 and 1970 by Yoshinori Asakawa [5,6]. Among the biopigments. Only one of the tested diarylheptanoids ( 1 ) was shown to significantly decrease the production of acyl homoserine lactones (AHL) in $P$. aeruginosa PAO1, more specifically, production of the long chain N-(3-oxododecanoyl)-l-HSL. On the other side, four diarylheptanoids (2-5) significantly reduced the synthesis of 2-alkyl-4-quinolones, part of the P. aeruginosa quinolone-mediated signaling system. To properly assess therapeutic potential of these compounds, their in vitro antiproliferative effect on normal human lung fibroblasts was determined, with doses affecting cell proliferation between 10 and $100 \mu \mathrm{g} / \mathrm{mL}$. This study confirms that the barks of green and black alders are rich source of phytochemicals with a wide range of biological activities that could further be exploited as natural agents against bacterial contaminations and infections.

Supporting information available online at http://www.thieme-connect.de/products

best-known linear diarylheptanoids from Alnus species are oregonin, platyphylloside, hirsutenone, and platyphyllenone ( $\bullet$ Fig. $\mathbf{1})$. They are isolated from black and gray alder (oregonin, platyphylloside, hirsutenone) and green alder (platyphyllenone) and are well known for their anticancer, anti-inflammatory, and antioxidative properties [7-12].

Green alder [Alnus viridis (Chaix) DC.] is a bush, 3-5 $\mathrm{m}$ tall, found in the mountains of central Europe (Alps) and the Balkan peninsula [13]. In Serbia, Alnus viridis (Chaix) DC. ssp. viridis can be found only in the east regions (Mt. Stara Planina), mostly near creeks, at an altitude of 1300-2100 m [14]. Black alder [Alnus glutinosa (L.) Gaertn.] is a tree, up to $25 \mathrm{~m}$ tall, that thrives in moist soil, near creeks and rivers, at an altitude up to $600 \mathrm{~m}$, and is widespread in Europe, the Mediterranean, 
southeastern Asia, and the Caucasus Mountains. In Serbia, it can be found mostly in the central and west regions, always near creeks and rivers [14].

Green and black alders have been the focus of our research as exceptionally rich sources of phytochemicals $[15,16]$. Investigated diarylheptanoids were previously isolated from the $\mathrm{CHCl}_{3} / \mathrm{MeOH}$ (1:1) extracts of the barks of the green and black alders and were chemically characterized $[10,17,18]$. They were the most common diarylheptanoids in these extracts. Poor to moderate antibacterial activity previously observed with these compounds [19] led us to examine their activity on bacterial communication within this study. Bacterial cell-to-cell signaling, so-called quorum sensing (QS), is involved in the regulation of virulence expression and biofilm development, traits that are crucial for pathogenicity and the interaction with colonization of eukaryotic hosts $[20,21]$. Among gram-negative bacteria, QS is frequently mediated by $\mathrm{N}$-acyl-L-homoserine lactone (AHL) signal molecules [22-24]. Virulence factors of important human pathogens such as $P$. aeruginosa are regulated in this manner [25,26]. P. aeruginosa has two AHL-mediated QS systems, namely las and rhl, and one quinolone (AHQs)-mediated signaling system [25,26]. The las system consists of a LasR regulator and the cognate autoinducer $\mathrm{N}$-(3-oxododecanoyl)-1-HSL (3-oxo-C12-HSL), while the rhl system consists of RhlR and the autoinducer N-butyryl-l-HSL (C4-HSL). These two AHL-mediated systems regulate the expression of many virulence factors, including LasA protease, phospholipase, exotoxin A, pyocyanin, rhamnolipids, and elastase, and also regulate the development of biofilms, while AHQs signaling, apart from regulating numerous virulence genes in common with AHLs, regulates genes involved in iron scavenging $[25,26]$. Compounds that attenuate virulence, without killing or a pronounced effect on growth, offer an alternative therapeutic target with less possibility of resistance development [24]. Inhibitors can disrupt QS in various ways, such as by acting as enzymes (e.g., AHL-lactonase or AHL-acylase) that destroy signal molecules, as enzymes that degrade LuxR protein, the receptor for QS signaling molecules, or as AHL mimics that compete and block signal molecules [27,28].

Plants are constantly exposed to bacterial infections. It is therefore logical to expect that plants have developed sophisticated chemical mechanisms to combat pathogens. Indeed, mushrooms $[29,30]$ and various plant extracts have been reported as efficient in bacterial QS inhibiting activity [31-33]. In this study, as a continuation of our studies on diarylheptanoids from plant sources, we have examined the effect of a series of the seven most common diarylheptanoids from black and green alders using two model bioreporter strains: Pseudomonas aeruginosa PAO1, including biosensors derived from it, and Chromobacterium violaceum CV026. PAO1 is a strain of $P$. aeruginosa, a gram-negative swarming opportunistic pathogen that usually forms persistent biofilms. It is a primary cause in infections associated with cystic fibrosis $(\mathrm{CF})$, burn wounds and the use of catheters and other medical devices, and a major cause of nosocomial infections [34]. Its biofilm forming ability leads to an increased tolerance to antibiotics and the persistence of chronic infections $[35,36]$. $P$. aeruginosa is often expanded by food, so natural agents suppressing their communication and influencing persistence and virulence are highly sought after. CV026 is a derivative of the gram-negative bacterium $C$. violaceum, commonly found in soil and water [37]. Wild-type $C$. violaceum produces the characteristic purple pigment, violacein, when AHL signaling molecules reach a threshold level [38]. Based on this readily observed pig-

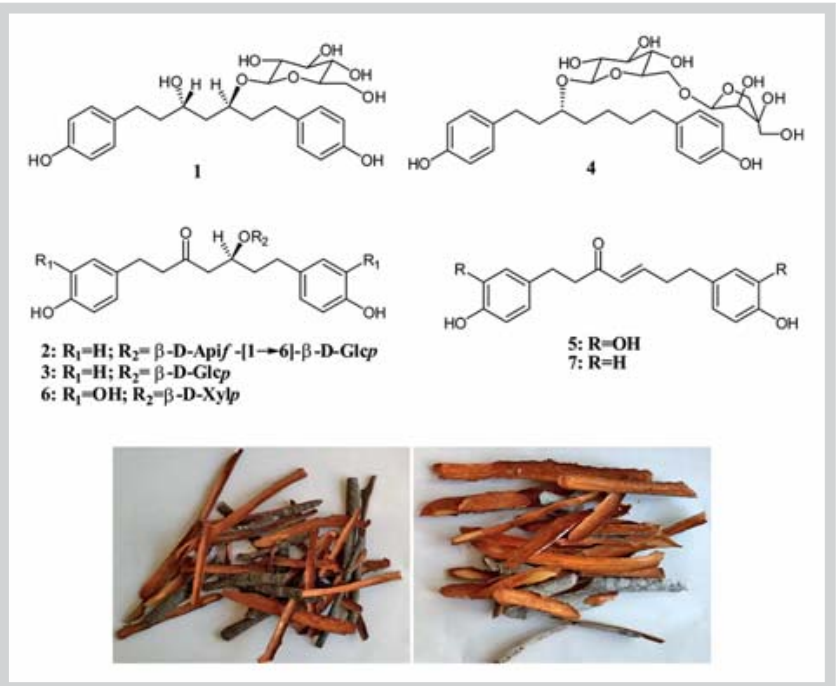

Fig. 1 Investigated diarylheptanoids (top) and barks of black alder (left) and green alder (right). (1S,3R)-3-Hydroxy-5-(4-hydroxyphenyl)-1-[2-(4hydroxyphenyl)ethyl]pentyl-O- $\beta$-D-glucopyranoside (1), (5S)-1,7-bis(4hydroxyphenyl)-5-O- $\beta$-D-apiofuranosyl( $1 \rightarrow 6)$ - $\beta$-D-glucopyranosyloxyheptan-3-one (2), platyphylloside (3), aceroside VIII (4), hirsutenone (5), oregonin (6), and platyphyllenone (7). (Color figure available online only.)

mentation phenotype, $C$. violaceum strains can be used to detect various aspects of AHL-mediated QS activity [39]. The CV026 strain harbors a LuxR receptor homologue and a corresponding QS-controlled promoter fused to a violacein production associated gene cluster and it is unable to produce violacein unless exogenous AHLs are supplied [37]. In addition, to further evaluate the safety for potential application of selected diarylheptanoids, in vitro antiproliferative activity of these compounds was determined.

\section{Results and Discussion}

$\nabla$

In this work, diarylheptanoids from the two plant species, green and black alders, were examined for anti-QS activity. Diarylheptanoids from the green alder were (1S,3R)-3-hydroxy-5-(4hydroxyphenyl)-1-[2-(4-hydroxyphenyl)ethyl]pentyl- $0-\beta$-D-

glucopyranoside (1), (5S)-1,7-bis(4-hydroxyphenyl)-5-O- $\beta$-Dapiofuranosyl $(1 \rightarrow 6)-\beta$-D-glucopyranosyloxyheptan-3-one (2), platyphylloside (3), aceroside VIII (4), and platyphyllenone (7). Platyphylloside (3), hirsutenone (5), and oregonin (6) were diarylheptanoids originated from the black alder. Platyphylloside (3) was isolated from both green and black alder barks ( $\bullet$ Fig. 1). The minimal inhibitory concentrations (MICs) of seven investigated diarylheptanoids against P. aeruginosa ATCC 27853 and $P$. aeruginosa PAO1 planktonically grown cells were in the range of 125 to $500 \mu \mathrm{g} / \mathrm{mL}$ (Table S1, Supporting Information) and comparable or slightly higher to those previously determined MIC values against $P$. aeruginosa NCTC6750 [17]. Their effect on $P$. aeruginosa PAO1 biofilm formation was tested at subinhibitory concentrations (50\% of determined MICs [19] (Table S1, Supporting Information) and results showed that compounds 1-4 had a high potential to inhibit the early formation of biofilms ( Fig. 2). Compound 3 reduced biofilm formation by $40 \%$ in comparison to the DMSO control, compound 1 by 60\% (similar to the positive control streptomycin), while a reduction in the 


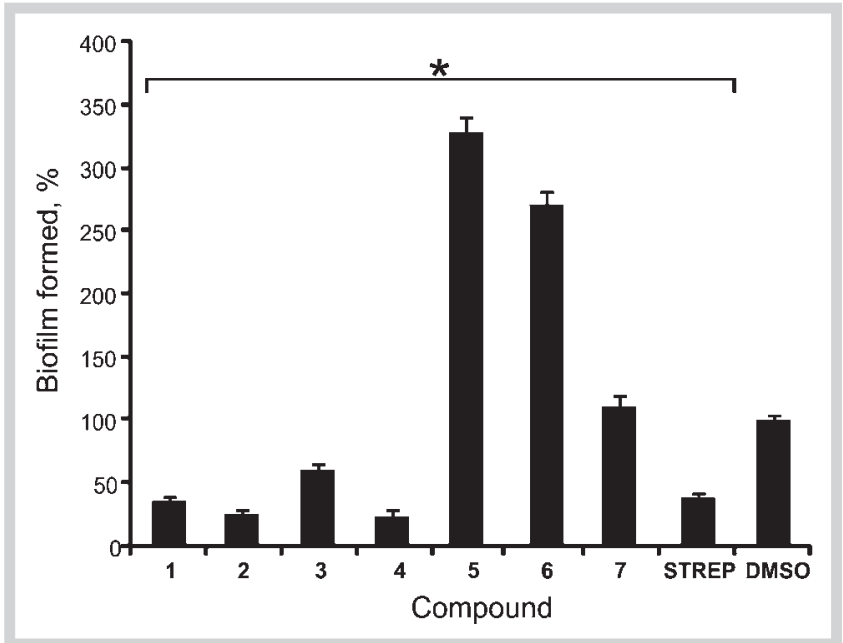

Fig. 2 P. aeruginosa PAO1 biofilm formation in the presence of subinhibitory concentrations ( $0.5 \mathrm{MIC}$ values) of diarylheptanoids and the antibiotic streptomycin (STREP). The biofilm formation in the presence of DMSO was considered to represent $100 \%$ biofilm formation. The experiment was done in quintuplicate and repeated two times.

presence of $\mathbf{2}$ and $\mathbf{4}$ was around 70\%. Compound $\mathbf{7}$ had no capacity to prevent biofilm formation, and, surprisingly, compounds 6 and 5 exhibited a stimulatory effect with 2.5-fold and 3-fold higher biofilm formation, respectively, at the concentration tested ( $\odot$ Fig. 2).

Apart from QS, the initiation of biofilm formation by P. aeruginosa depends on two cell-associated structures: the flagellum and type IV pili $[40,41]$. The flagellum is responsible for swimming motility, while the type IV pili are responsible for twitching motility [42]. Both types of motility are important in the initial stages of biofilm formation by $P$. aeruginosa $[40,41]$. Therefore, we tried to determine if investigated diarylheptanoids influence either one or both motilities (Table S2, Supporting Information). All diarylheptanoids reduced the twitching motility of $P$. aeruginosa (Fig. S1, Supporting Information). Colonies of $P$. aeruginosa PAO1 grown without diarylheptanoids were flat with a rough appearance displaying irregular colony edges, and hazy zones were surrounding these colonies (Fig. S1 J, Supporting Information). Untreated cells grew in a very thin layer. After 2 days of incubation at ambient temperature, colony expansion occurred very rapidly due to twitching motility (Table S2, Supporting Information). Bacteria that were grown in the presence of diarylheptanoids were incapable of producing such twitching zones and had almost round, smooth, regular colony edges, while protrusions were reduced both in size $(24-120 \mu \mathrm{m})$ and in number (Fig. S1 A-G, Supporting Information), and the colony diameters of swimming zones were also reduced. In comparison, antibiotics such as streptomycin reduced the protrusion (Fig. S1 H, Supporting Information), while the presence of ampicillin, which P. aeruginosa PAO1 is resistant to, had no significant effect on protrusion (Fig. S1I, Supporting Information).

To evaluate the potential of diarylheptanoids as inhibitors of AHLbased QS signal molecules, two biosensor reporter strains were used: P. aeruginosa PAO1 and C. violaceum CV026. P. aeruginosa PAO1 produces a blue-green pigment pyocyanin under the control of AHL, while $C$. violaceum CV026 is a white, violacein negative, double mini-Tn mutant that has no constitutive ability of violacein pigment production, but CV026 can sense exogenously

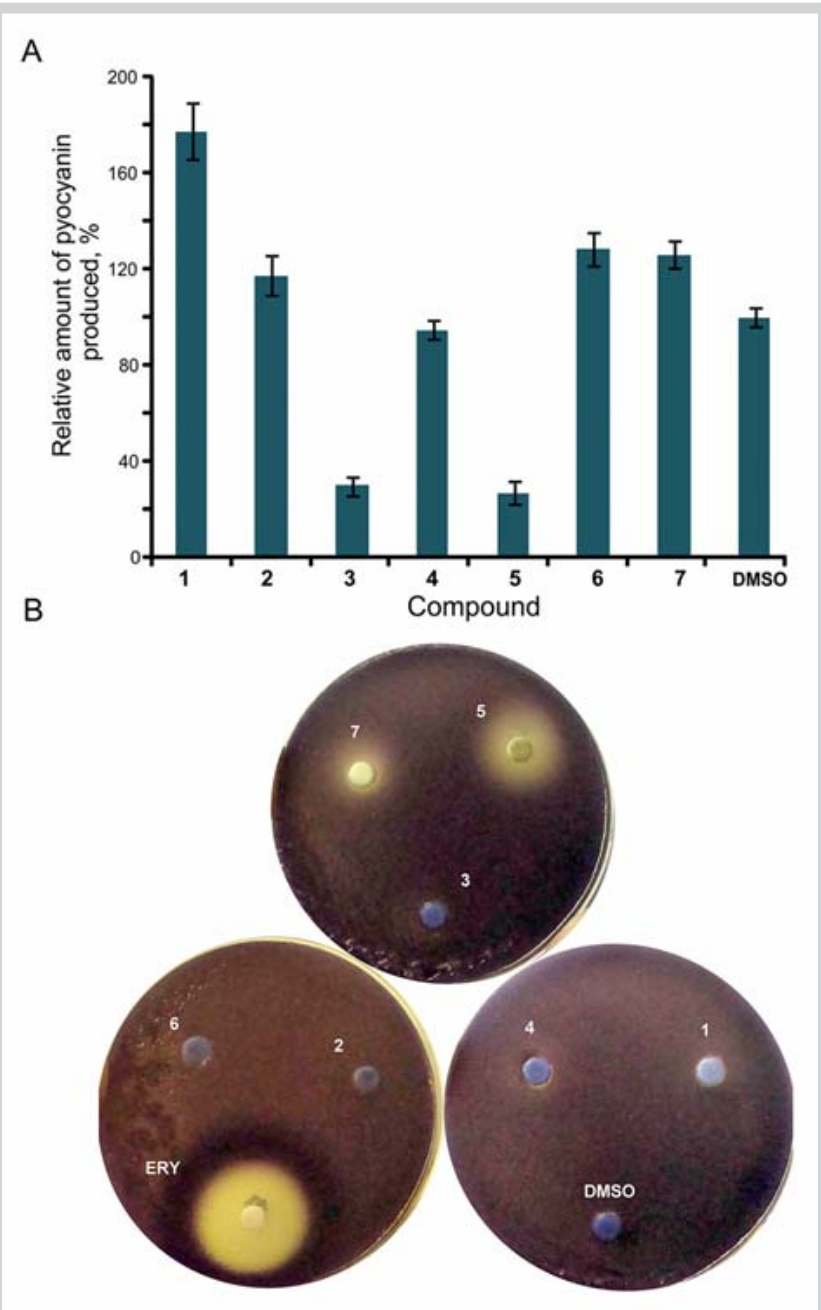

Fig. 3 A Effects of diarylheptanoids $(50 \mu \mathrm{g} / \mathrm{mL})$ on the production of pyocyanin by $P$. aeruginosa PAO1. B Bioassay of inhibition of violacein synthesis in C. violaceum CV026 by diarylheptanoids ( $250 \mu \mathrm{g} / \mathrm{disc})$. Compounds $\mathbf{5}$ and $\mathbf{7}$ showed considerable inhibition of violacein production. A colorless, but not clear zone around the discs indicated anti-QS activity. The negative and positive controls in the bioassay were solvent DMSO and the antibiotic erythromycin (ERY). (Color figure available online only.)

added AHLs and responds by producing purple violacein [37,38, 43].

The effect of diarylheptanoids on pyocyanin production in P. aeruginosa PAO1 was tested in a flask assay at the concentration of $50 \mu \mathrm{g} / \mathrm{mL}$ ( $\odot$ Fig. 3A). Of the seven investigated compounds, diarylheptanoids $\mathbf{3}$ and $\mathbf{5}$ significantly reduced pyocyanin production by $70 \%$ and $73 \%$, respectively, whereas all of the others diarylheptanoids stimulated pyocyanin production (in the range of 17-77\%) compared to the control P. aeruginosa PAO1 (DMSO). Diarylheptanoids 5 and 7 demonstrated considerable antagonistic activity on QS in CV026 when $100 \mu \mathrm{g}$ of the test compound was applied per disc. Inhibition of violacein production with $\mathbf{5}$ and 7 was clearly visible as a colorless halo around the discs ( Fig. 3B), not as strong as erythromycin, but significant to suggest that these diarylheptanoids could be blocking AHL-QS signaling. Many mechanisms of actions have been proposed to interfere with the QS inhibition, such as inhibition of biosynthesis of autoinducer molecules, inactivation or degradation of the autoinducer, interference with the signal receptor, and inhibition 

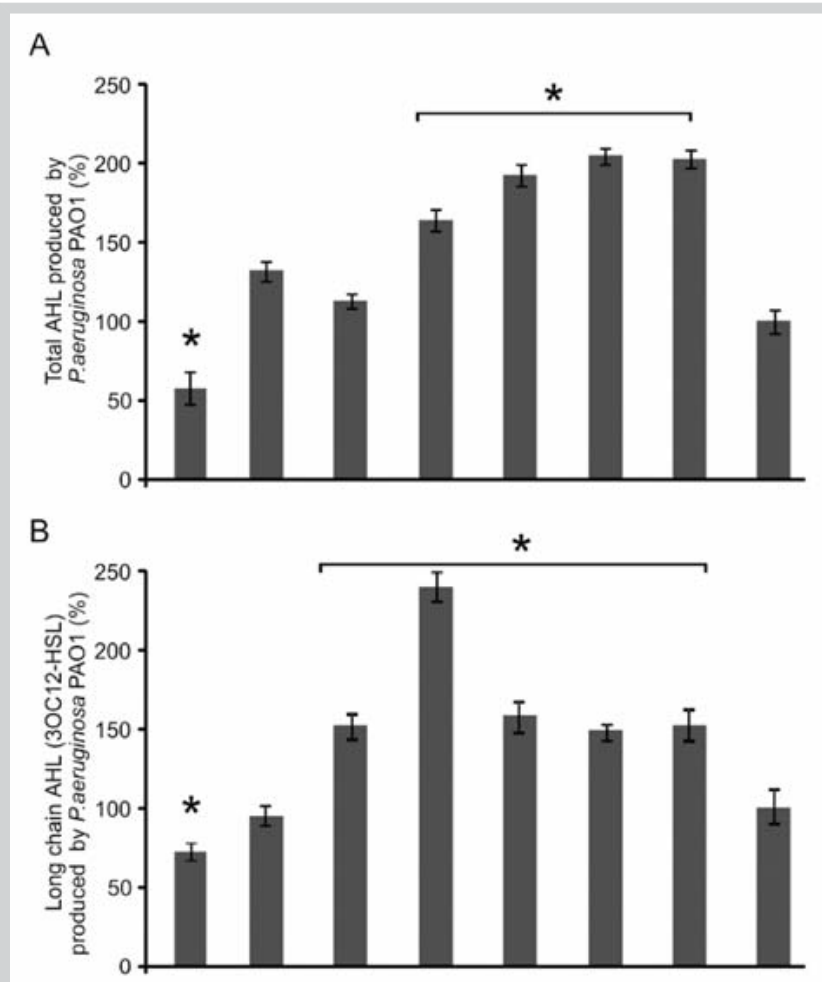

c

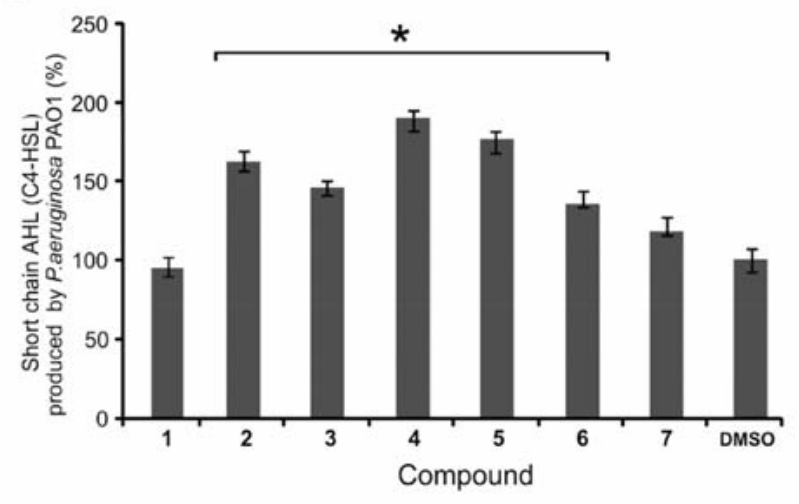

Fig. 4 Effect of diarylheptanoids $(50 \mu \mathrm{g} / \mathrm{mL})$ on acyl homoserine lactone $(\mathrm{AHL})$ production in $\mathrm{P}$. aeruginosa PAO1. A Total AHLs; B Long chain (3OC12-HSL) and C short-chain (C4-HSL). The PAO1 $\triangle$ rhllpKD-rhlA reporter strain was used to directly measure the levels of C4-HSL, and the PA14R3AlasIPrsal: lux strain was used to directly measure the levels of 30C12HSL in the culture supernatants of $P$. aeruginosa PAO1. * Represents statistically significant differences between compounds. DMSO served as the negative control.

of the genetic regulation system [44]. Hirsutenone (5) had the ability to inhibit synthesis of both biopigments.

To test whether the diarylheptanoids influenced AHL production in $P$. aeruginosa PA01, we have grown this strain in the presence of $50 \mu \mathrm{g} / \mathrm{mL}$ diarylheptanoid and then performed the extraction of the AHLs. In the assay with $C$. violaceum CV026 as a reporter organism of QS, five out of seven AHL extracts from P. aeruginosa PAO1 manifested an unambiguous modulatory effect on violacein synthesis ( Fig. 4). Interestingly, a notable stimulatory effect on overall AHL production in $P$. aeruginosa PAO1, in the range of $150 \%$ to $200 \%$ compared to the negative control (DMSO; - Fig. 4A), was observed when four compounds (4-7) were sup-

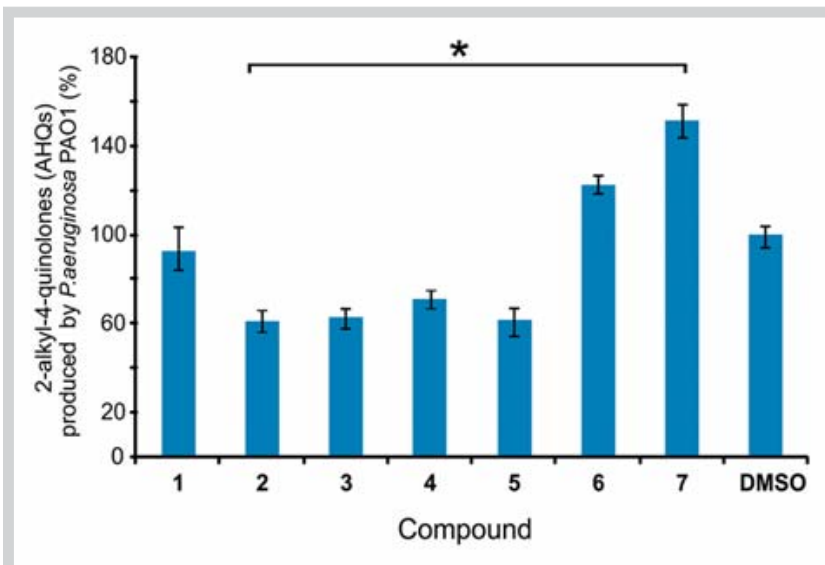

Fig. 5 Effect of diarylheptanoids $(50 \mu \mathrm{g} / \mathrm{mL})$ on AHQs production in P. aeruginosa PAO1. Detection of AHQs (PQS and HHQ) was performed by the biosensor PAO1 $\triangle \mathrm{pqsA}$ mini-CTX luxPpqsA. Extract of $P$. aeruginosa $\mathrm{PAO1}$ grown in the presence of DMSO served as the negative control. * Represents statistically significant differences between compounds. DMSO served as the negative control. (Color figure available online only.)

plied to the medium in these concentrations. When compound 1 was used, it reduced overall AHL production in $P$. aeruginosa PAO1 by $40 \%$ ( Fig. 4A).

To differentiate the effects of seven diarylheptanoids on $r h l$ and las QS systems in P. aeruginosa PAO1, two biosensors strains were included: PA14-R3 $\Delta$ lasIPrsal:lux for the detection of a longchain AHL (3-oxo-C12-HSL) and PAO1 $\triangle$ rhlIpKD-rhlA for the detection of a short-chain AHL (C4-HSL; Fig. 4B-C). Only compound 1 significantly reduced the production of 3-oxo-C12-HSL by $35 \%$, possibly accounting for its biofilm preventing activity ( Fig. 2). Most of the other diarylheptanoids stimulated both the production of 3-oxo-C12-HSL and C4-HSL, suggesting that their observed activities on $P$. aeruginosa PAO1 biofilm and biopigment synthesis occurred via different mechanisms of action. $P$. aeruginosa, as some other bacterial species, has multiple interdependent QS systems. It produces diverse 2-alkyl-4-quinolones (AHQs), which act as QS signal molecules and are also involved in the regulation of many virulence factors. PQS has been shown to control the production of multiple virulence determinants, including elastase, pyocyanin, rhamnolipids, and biofilm development $[20,25,28,45]$. Biosensor strain P. aeruginosa PAO1 $\triangle \mathrm{pqsA}$ mini-CTX luxPpqsA was used to evaluate the influence of selected diaryheptanoids to AHQs production in $P$. aeruginosa PAO1 ( Fig. 5). Compounds 2-5 significantly reduced the production of 2-alkyl-4-quinolones in $P$. aeruginosa PAO1 cultures grown in the presence of these compounds at $50 \mu \mathrm{g} / \mathrm{mL}$ when compared to the negative control (DMSO treated). On the other side, extracts from $P$. aeruginosa PAO1 cultures cultivated with compounds 6 and 7 showed a stimulatory effect of $120 \%$ to $150 \%$, respectively ( Fig. 5). These results indicated that diarylheptanoids more efficiently modulate the quinolone-mediated QS system in P. aeruginosa PAO1. The quinoline system is usually transferred via extremely hydrophobic molecules, usually in membrane vesicles $[25,26]$, so structural differences of selected quite polar diarylheptanoids ( $\bullet$ Fig. 1 ) could not account for the observed differences in the QS modulating activity.

In the present study, we have evaluated antiproliferative effects of the seven diarylheptanoids against MRC5 cells line (human lung fibroblasts) using the MTT assay. Doxorubicin was used as a 


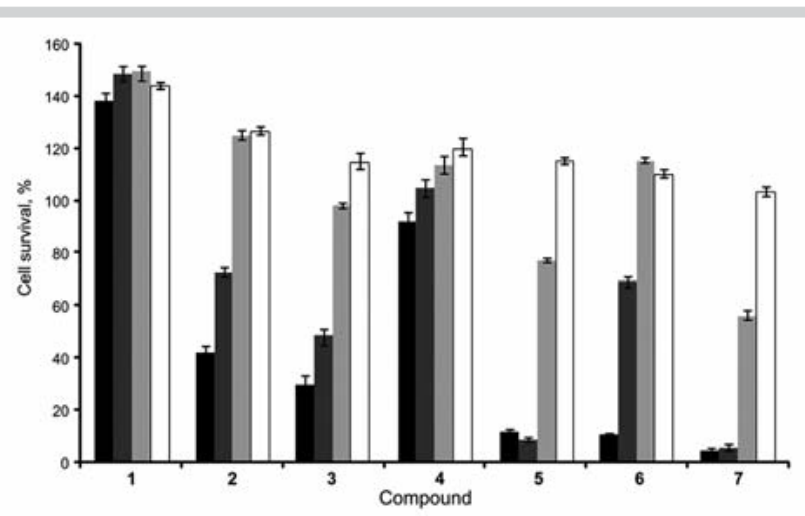

Fig. 6 Antiproliferative activity of diarylheptanoids on the growth of the MRC5 cell line. Cells were treated with $1 \square, 10 \square, 50 \square$, and $100 \square \mu \mathrm{g} / \mathrm{mL}$ of each tested compound for $48 \mathrm{~h}$. Doxorubicin was used as a positive control. Viability was measured by the MTT assay. Values are expressed as the percent of cell survival and are based on quadruplicate tests performed twice, with mean values shown and standard deviations depicted by the vertical bars.

positive control. The results of the MTT assay showed that diarylheptanoids could inhibit cell proliferation in a concentrationdependent manner ( $\bullet$ Fig. 6). Five tested compounds, 2, 3, and 5-7, were cytotoxic when applied in high concentrations, especially 5-7 exhibited a stronger cytotoxic effect than doxorubicin at the concentrations of $50 \mu \mathrm{g} / \mathrm{mL}$ and $100 \mu \mathrm{g} / \mathrm{mL}$. They were able to inhibit proliferation of the fibroblasts cell line between $95 \%$ and $60 \%$. Also, when supplied in the concentration of $50 \mu \mathrm{g} / \mathrm{mL}$, compounds 7 and 5 exhibited a cytotoxic effect, inhibiting fibroblast proliferation at about $95 \%$. These five compounds were active towards MRC5 cells with $\mathrm{IC}_{50}$ values of $10,20,50,60$, and $70 \mu \mathrm{g} / \mathrm{mL}$, respectively, whereas compounds $\mathbf{1}$ and $\mathbf{4}$ did not show any antiproliferative activity at the tested concentrations ( Fig. 6). Therefore, 1 and 4 can be considered safe in concentrations of up to $250 \mathrm{mg} / \mathrm{mL}$ (which was the highest concentration included in the screen; results not shown). They also efficiently inhibited formation of $P$. aeruginosa biofilms ( $\odot$ Fig. 2) and successfully inhibited the production of QS signaling molecules ( Fig. 4B and Fig. 5). Thus, these two diarylheptanoids can be further examined for application in antimicrobial therapy.

Platyphylloside (3), previously isolated from the inner bark of Betula papyrifera Marshall, exhibited $\mathrm{IC}_{50}$ concentrations with three different cell lines A549, DLD-1, and WS1 between 10.3 and $13.8 \mu \mathrm{M}$ [45]. Similarly, according to literature data, hirsutenone (5) was isolated from various plant sources and was found to be cytotoxic against a number of different cell lines including macrophages, HeLa, and the HT-29 human colon cancer cell line $[46,47]$. This was also in accordance with our previous data that defined $\mathbf{3}$ and $\mathbf{5}$ as compounds with anticancer potential, being active against human lung carcinoma cell lines [10].

QS plays a critical role in bacterial virulence and survival, which makes this signaling pathway an attractive target for antimicrobial drug development. This has afforded a novel opportunity to control the activity of gram-negative infecting bacteria by other means than interfering with their growth, posing a lower chance for the development of resistance. We have shown that compounds, particularly diarylheptanoids, interfering with bacterial communication systems are present in the bark of green and black alders. Our data also confirmed that multiple families of
QS pathways interactively regulate different gene expressions in $P$. aeruginosa PAO1, and that although structurally similar, diarylheptanoids cause different effects on phenotypic characteristics under QS control. Overall, selected diarylheptanoids may not have a wide therapeutic window, but further research into their or other diarylheptanoids of plant origin should be carried out in the direction of bacterial anti-QS application.

\section{Material and Methods}

$\nabla$

\section{Plant material and compounds origin}

Diarylheptanoids investigated in this work were previously isolated from the $\mathrm{CHCl}_{3} / \mathrm{MeOH}(1: 1)$ extracts of the black and green alder barks from Serbia $[17,18]$. Silica gel column chromatography followed by semipreparative reversed-phase HPLC were the techniques used for isolation. The structures of the diarylheptanoids were elucidated by means of 1D and 2D NMR, IR, UV, and HR-ESI-MS. Prior to investigation of the biological activity, all tested diarylheptanoids were checked for their purity by HPLC (at $280 \mathrm{~nm}$ ) and ${ }^{1} \mathrm{H}$ NMR, and it was higher than $98 \%$.

\section{Bacterial strains, growth media, and culture conditions}

P. aeruginosa ATCC 27853 was obtained from the Amerycan Type Culture Collection, while $P$. aeruginosa PA01, P. aeruginosa PAOJP2, P. aeruginosa PA14-R3, and PAO1 1 pqsAmini-CTXluxPpqsA were kindly provided by Dr. Livia Leoni, Department of Biology, University Roma Tre, Italy. Biosensor strain C. violaceum CV026 [37] was provided by Prof. Vittorio Venturi (ICGB, Trieste, Italy). Bacteria were routinely grown in Luria-Bertani (LB) medium [ $1 \%(\mathrm{w} / \mathrm{v}) \mathrm{NaCl}, 1 \%(\mathrm{w} / \mathrm{v})$ tryptone, $0.5 \%(\mathrm{w} / \mathrm{v})$ yeast extract] with or without agar $(1.5 \% \mathrm{w} / \mathrm{v})$, then were shaken $(180 \mathrm{rpm})$ at $37^{\circ} \mathrm{C}$. Tryptone soy broth (TSB; Oxoid) was used for growth of $P$. aeruginosa PAO1 in the assay of biofilm formation. Mueller-Hinton agar ( $\mathrm{MH}$; Oxoid) was used to determine the motility of $P$. aeruginosa PAO1. When required, the antibiotics kanamycin (kanamycin sulfate from Streptomyces kanamyceticus, BioReagent; Sigma-Aldrich, purity $>95 \%$ ), streptomycin (Streptomycin sulfate salt, BioReagent; Sigma-Aldrich, purity $>96 \%$ ), and tetracycline (BioReagent; Sigma-Aldrich, purity $>96 \%$ ) were incorporated into the growth medium at a concentration of $30 \mu \mathrm{g} / \mathrm{mL}$ or $200 \mu \mathrm{g} /$ $\mathrm{mL}$ in the case of kanamycin, $20 \mu \mathrm{g} / \mathrm{mL}$ for streptomycin, and $100 \mu \mathrm{g} / \mathrm{mL}$ for tetracycline.

\section{Activity of compounds on Pseudomonas aeruginosa PA01 biofilm formation}

To determine the MICs of each diarylheptanoid against $P$. aeruginosa PAO1, a standard broth microdilution method was used in LB broth [48]. Tested compounds were included in concentrations from $0.9 \mu \mathrm{g} / \mathrm{mL}$ to $500 \mu \mathrm{g} / \mathrm{mL}$. The carrier solvent DMSO was used as a control. Cell growth was measured via optical density at $600 \mathrm{~nm}\left(\mathrm{OD}_{600 \mathrm{~nm}}\right)$ using a Tecan Infinite 200 Pro multiplate reader (Tecan Group Ltd.) plate reader after $24 \mathrm{~h}$ incubation at $37^{\circ} \mathrm{C}$.

P. aeruginosa biofilms were grown in TSB medium without shaking conditions. The effect of diarylheptanoids on biofilm forming ability was tested at concentrations of $50 \%$ of the determined MIC (0.5 MIC) for each compound, on polystyrene flat-bottomed microtiter 96-well plates as previously described, with some modifications [49]. Briefly, the overnight culture of $P$. aeruginosa was diluted in a fresh $\mathrm{LB}$ medium to $\mathrm{OD}_{600 \mathrm{~nm}}=0.2$ and $100 \mu \mathrm{L}$ of the diluted culture with the appropriate diarylheptanoid at the 
concentration of $0.5 \mathrm{MIC}$ was added to the plate. After incubation for $24 \mathrm{~h}$ at $37^{\circ} \mathrm{C}$, the plate was washed twice with sterile water, dried, and stained for $30 \mathrm{~min}$ with $0.4 \%$ crystal violet in order to determine biofilm formed. Stained cells were washed with sterile water to remove the unbound crystal violet. After drying, $150 \mu \mathrm{L}$ of $30 \%(v / v)$ acetic acid were added to solubilize the dye. After $10 \mathrm{~min}$, the content of the wells was homogenized and the OD of the samples was measured at $550 \mathrm{~nm}$ using a Tecan Infinite 200 Pro multiplate reader (Tecan Group Ltd.). The experiment was done in quintuplicate and repeated two times.

\section{Effect of diarylheptanoids on twitching and \\ flagella motility of Pseudomonas aeruginosa PA01}

Twitching and motility of $P$. aeruginosa PAO1 was assessed after the growth in the presence or absence of diarylheptanoids (10$15 \mu \mathrm{g} / \mathrm{mL})$ and streptomycin $(20 \mu \mathrm{g} / \mathrm{mL})$. P. aeruginosa PAO1 cells were washed twice with sterile PBS and resuspended in PBS at $1 \times 10^{8} \mathrm{cfu} / \mathrm{mL}\left(\mathrm{OD}_{600 \mathrm{~nm}}=0.1\right)$. Cells were stabbed into a nutrient agar plate with a sterile toothpick and incubated overnight at $37^{\circ} \mathrm{C}$. Plates were removed from the incubator and incubated at room temperature for two more days. Colony edges and the zone of motility were measured with a light microscope $[40,41]$. An assay to test flagella-mediated motility was performed as previously described $[40,41]$. Test compounds were mixed into $10 \mathrm{~mL}$ of molten $\mathrm{MH}$ medium and poured immediately over the surface of a solidified LB plate as an overlay. The plate was point inoculated with an overnight culture of $P$. aeruginosa PAO1 once the overlaid agar had solidified and then was incubated at $37^{\circ} \mathrm{C}$ for 3 days. The extent of swimming was determined by measuring the area of the colony [32]. The experiment was done in triplicate and repeated two times. The colony diameters were measured three times in different directions, and values are presented as the mean values \pm SE (standard error).

\section{Effect of diarylheptanoids on pyocyanin synthesis in Pseudomonas aeruginosa PAO1}

Overnight culture of $P$. aeruginosa PAO1 grown in Kings Medium A (Himedia) was diluted to $\mathrm{OD}_{600 \mathrm{~nm}}=0.2(5 \mathrm{~mL})$. Different diarylheptanoids at a concentration of $50 \mu \mathrm{g} / \mathrm{mL}$ were added to the flasks with $P$. aeruginosa PAO1 and incubated at $37^{\circ} \mathrm{C}$ for $24 \mathrm{~h}$. Cultures were then extracted with chloroform $(3 \mathrm{~mL})$ and the chloroform layer was transferred to a fresh tube and mixed with $0.2 \mathrm{M} \mathrm{HCl}(1 \mathrm{~mL})$ giving it a pink to deep red color, indicating the presence of pyocyanin. To determine the amount of pyocyanin, the absorbance was measured at $520 \mathrm{~nm}$ [50]. The experiment was done in triplicate and repeated two times. The values are expressed as a ratio $\left(\mathrm{OD}_{520} / \mathrm{OD}_{600}\right) \times 100$.

\section{Effect of diarylheptanoids on violacein synthesis in Chromobacterium violaceum CV026}

C. violaceum CV026, mini-Tn5 mutant, depends on exogenous AHLs for violacein production, was used as an indicator organism to monitor QS inhibition in a disc diffusion assay [37]. Briefly, semisolid LB agar $(0.3 \%, \mathrm{w} / \mathrm{v} ; 5 \mathrm{~mL})$ was seeded with $50 \mu \mathrm{L}$ of an overnight culture of $C$. violaceum $\mathrm{CV} 026$ supplemented by N-hexanoyl-L-homoserine lactone (Sigma) to a final concentration of $5 \mu \mathrm{M}$ and poured over the surface of LB agar plates. When the overlaid agar had solidified, sterilized discs containing $200 \mu \mathrm{g}$ of each compound and erythromycin $(50 \mu \mathrm{g})$ as positive control (Sigma-Aldrich; Bioreagent, purity $>95 \%$ ) were placed on the plates. Petri dishes were incubated in the upright position overnight $\left(30^{\circ} \mathrm{C}\right)$ and examined for violacein synthesis. Inhibition of violacein synthesis was defined by the presence of white haloes in a purple background.

\section{Assays for acyl homoserine lactones production}

For the extraction of AHLs, P. aeruginosa PAO1 was grown in LB broth at $37^{\circ} \mathrm{C}$ for $24 \mathrm{~h}$ and supplemented with the appropriate test compound to a final concentration of $50 \mu \mathrm{g} / \mathrm{mL}$ from the DMSO stock solution. The control containing the equivalent amount of DMSO was also included. After $24 \mathrm{~h}$ of growth, the optical density of the culture at $540 \mathrm{~nm}\left(\mathrm{OD}_{540 \mathrm{~nm}}\right)$ was determined and the cells were centrifuged. Supernatants $(20 \mathrm{~mL})$ from these cultures were extracted with the same volume of acidified ethyl acetate [acetic acid, $0.1 \%(\mathrm{v} / \mathrm{v})$ ] for $10 \mathrm{~min}$ with shaking and centrifuged to separate the aqueous and ethylacetate phases. The ethylacetate phase was transferred to a clean bottle and the solvent was removed under reduced pressure. The remaining residue was weighted and dissolved in the same solvent in an appropriate amount that corresponded to the following ratio: $1 \mu \mathrm{L}$ of final extract corresponding to $1 \times 10^{9}$ cells of the original culture [51]. Experiments were performed in triplicate. Concentrated extracts were used in the AHL assays. Semisolid LB agar $(0.3 \%, \mathrm{w} / \mathrm{v}$; $5 \mathrm{~mL}$ ) was seeded with $50 \mu \mathrm{L}$ of an overnight culture of $C$. violaceum CV026 and poured over the surface of LB agar plates. When the overlaid agar had solidified, sterilized discs containing $10 \mu \mathrm{L}$ of each AHL extract were placed on the surface of the plates. These petri dishes were incubated in the upright position overnight $\left(30^{\circ} \mathrm{C}\right)$ and examined for the stimulation of violacein synthesis. QS induction was detected as purple pigmentation of the bioreporter strain grown around the discs. Measurements were made from the outer edge of the discs to the edge of the zones of QS stimulation or QS inhibition. The assays were performed in triplicate.

For the micro-volumetric determination of long-chain (3-oxoC12-HSL) and short-chain AHL (C4-HSL) levels in P. aeruginosa PAO1 culture supernatants, cultures were grown overnight at $37^{\circ} \mathrm{C}$ in LB. Cultures were diluted $1: 1000$ in $10 \mathrm{~mL}$ LB in the presence of diarylheptanoids or DMSO and grown at $37^{\circ} \mathrm{C}$. After $6 \mathrm{~h}$ of growth, the $\mathrm{OD}_{600}$ was measured, and $2 \mathrm{~mL}$ of culture were centrifuged and the supernatant was filtered and stored at $-20^{\circ} \mathrm{C}$ until used. An aliquot of culture supernatants $(20 \mu \mathrm{l})$ was added to $180 \mu$ l of LB inoculated with P. aeruginosa PA14-R3 (measurements of 30C12-HSL) or P. aeruginosa PAOJP2 (measurements of $\mathrm{C} 4-\mathrm{HSL}$; final $\left.\mathrm{OD}_{600}=0.045\right)[52,53]$. Plates were incubated at $37^{\circ} \mathrm{C}$ with shaking, and cell density $\left(\mathrm{OD}_{600}\right)$ and bioluminescence (light counts per second, LCPS) were simultaneously measured after $4 \mathrm{~h}$ of incubation using a Tekan Infinite 200 Pro multiplate reader (Tecan Group Ltd.). Luminescence values were normalized per cell density.

\section{2-Alkyl-4-quinolones production assay}

For the detection and quantification of QS molecules 2-alkyl-4quinolones (AHQs), such as 2-heptyl -3-hydroxy-4 quinolone (PQS) and 2-heptyl-4-quinolone (HHQ), which represent the major $P$. aeruginosa AHQ signal molecules present in bacterial culture supernatants, a lux-based $P$. aeruginosa AHQ sensor was employed in a liquid microtiter plate assay. A PAO1 $\triangle$ pqsA mini-CTX luxPpqsA biosensor was used for the detection and quantification of AHQ molecules extracted from $P$. aeruginosa PAO1 cultures as described previously [54]. 


\section{Antiproliferative assay}

Antiproliferative activities of diarylheptanoids were measured using the methods described previously [55]. MRC5 cells (human lung fibroblast, obtained from ATCC) were plated in a 96-well flat-bottom plate at a concentration of $1 \times 10^{4}$ cells per well grown in a humidified atmosphere of $95 \%$ air and $5 \% \mathrm{CO}_{2}$ at $37^{\circ}$ $\mathrm{C}$, and maintained as monolayer cultures in RPMI-1640 medium supplemented with $100 \mu \mathrm{g} / \mathrm{mL}$ streptomycin, $100 \mathrm{U} / \mathrm{mL}$ penicillin, and $10 \%(\mathrm{v} / \mathrm{v})$ FBS. After $24 \mathrm{~h}$ of MRC5 cells incubation, the media containing increasing concentrations of each tested diarylheptanoid $(1,10,50,100$, and $250 \mu \mathrm{g} / \mathrm{mL})$ were added to the cells. Control cultures received the solvent DMSO, and blank wells contained $200 \mu \mathrm{L}$ of growth medium. As a positive control, doxorubicin hydrochloride (Sigma-Aldrich, $98-100 \%$ purity by HPLC) was used because it is a commonly used chemotherapeutic drug for the treatment of acute leukemia, lymphomas, and different types of solid tumors such as breast, liver, and lung cancers. After $48 \mathrm{~h}$ of incubation, cell proliferation was determined using the MTT reduction assay. Cell proliferation was determined from the absorbance at $540 \mathrm{~nm}$ on a Tekan Infinite 200 Pro multiplate reader (Tecan Group Ltd.). The MTT assay was performed two times in four replicates and the results are presented as the percentage of the control (untreated cells) that was arbitrarily set to $100 \%$.

\section{Statistical analysis}

For each species, three samples were used and all of the assays were carried out in triplicate. The results are expressed as mean values and standard errors, and were analyzed using one-way analysis of variance (ANOVA) followed by Tukey's HSD test with $\alpha=0.05$. This analysis was carried out using SPSS v. 18.0 program.

\section{Supporting information}

Minimal inhibitory concentrations (MIC, $\mu \mathrm{g} / \mathrm{mL}$ ) of diarylheptanoids against $P$. aeruginosa planktonically grown cells, activity of diarylheptanoids on twitching and motility of $P$. aeruginosa PAO1 are available as Supporting Information.

\section{Acknowledgement}

\section{$\nabla$}

This study is financially supported by the Ministry of Education, Science and Technological Development of Republic of Serbia, Project Nos. 172053 and ON173048.

\section{Conflict of Interest}

The authors declare no conflict of interest.

\section{References}

1 Priyadarsini KI. The chemistry of curcumin: from extraction to therapeutic agent. Molecules 2014; 19: 20091-20112

2 Turrini E, Ferruzzi L, Fimognari C. Natural compounds to overcome cancer chemoresistance: toxicological and clinical issues. Expert Opin Drug Metab Toxicol 2014; 10: 1677-1690

3 Miłobędzka J, Kostanecki S, Lampe V. Zur Kenntnis des Curcumins. Ber Deut Chem Ges 1910; 43: 2163-2170

4 Gupta SC, Patchva S, Koh W, Aggarwal BB. Discovery of curcumin, a component of golden spice, and its miraculous biological activities. Clin Exp Pharmacol Physiol 2012; 39: 283-299

5 Asakawa Y, Genjida F, Hayashi T, Matsuura T. A new ketol from Alnus firma Sieb. et Zucc. (Betulaceae). Tetrahedron Lett 1969; 10: 3235-3237
6 Asakawa Y. Chemical constituents of Alnus firma (Betulaceae). 1. Phenyl propane derivatives isolated from Alnus firma. Bull Chem Soc Jpn 1970; 43: 2223-2229

7 Cheong LY, Suk S, Thimmegowda NR, Chung MY, Yang H, Seo SG Shwetha B, Kim JE, Kwon JY, Kim BY, Lee KW. Hirsutenone directly targets PI3K and ERK to inhibit adipogenesis in 3T3-L1 preadipocytes. J Cell Biochem 2015; 116: 1361-1370

8 Lee CS, Jang ER, Kim YJ, Myung SC, Kim W, Lee MW. Diarylheptanoid hirsutenone enhances apoptotic effect of TRAIL on epithelial ovarian carcinoma cell lines via activation of death receptor and mitochondrial pathway. Invest New Drugs 2012; 30: 548-557

9 Lee O, Kim J, Choi YW, Lee M, Park G, Oh C. Efficacy of oregonin investigated by non-invasive evaluation in a B16 mouse melanoma model. Exp Dermatol 2013; 22: 842-844

10 Novaković M, Pešić M, Trifunović S, Vucković I, Todorović N, PodolskiRenić A, Dinić J, Stojković S, Tešević V, Vajs V, Milosavljević S. Diarylheptanoids from the bark of black alder inhibit the growth of sensitive and multi-drug resistant non-small cell lung carcinoma cells. Phytochemistry 2014; 97: 46-54

11 Ponomarenko J, Trouillas P, Martin N, Dizhbite T, Krasilnikova J, Telysheva G. Elucidation of antioxidant properties of wood bark derived saturated diarylheptanoids: a comprehensive (DFT-supported) understanding. Phytochemistry 2014; 103: 178-187

12 Tung NH, Sun K, Fan JY, Shoyama Y, Han JY. Oregonin from the bark of Alnus japonica restrained ischemia-reperfusion-induced mesentery oxidative stress by inhibiting NADPH oxidase activation. Microcirculation 2014; 21: 688-695

13 Ball P. Alnus Miller. In: Tutin TG, Heywood VH, Burges NA, Valentine DH, Walters SM, Webb DA, editors. Flora Europaea 1. London: Cambridge University Press; 1964: 59-60

14 Jovanović B. Genus Alnus Hill. In: Josifović V, editor. Flora of Serbia Vol. II. Belgrade: Serbian Academy of Sciences and Arts; 1970: 102-105

15 Dinić J, Novaković M, Podolski-Renić A, Stojković S, Mandić B, Tešević $V$, Vajs $V$, Isaković A, Pesić $M$. Antioxidative activity of diarylheptanoids from the bark of black alder (Alnus glutinosa) and their interaction with anticancer drugs. Planta Med 2014; 80: 1088-1096

16 Dinić J, Randelović T, Stanković T, Dragoj M, Isakoviv A, Novakoviv $M$, Pesić $M$. Chemo-protective and regenerative effects of diarylheptanoids from the bark of black alder (Alnus glutinosa) in human normal keratinocytes. Fitoterapia 2015; 105: 169-176

17 Novaković $M$, Stanković $M$, Vučković I, Todorović N, Trifunović S, Apostolović D, Mandić $B$, Veljić $M$, Marin $P$, Tešević $V$, Vajs $V$, Milosavljević $S$. Diarylheptanoids from green alder bark and their potential for DNA protection. Chem Biodivers 2014; 11: 872-885

18 Novaković $M$, Stanković $M$, Vučković I, Todorović N, Trifunović S, Tešević $V$, Vajs V, Milosavljević S. Diarylheptanoids from Alnus glutinosa bark and their chemoprotective effect on human lymphocytes DNA. Planta Med 2013; 79: 499-505

19 Novaković M, Novaković I, Cvetković M, Sladić D, Tešević V. Antimicrobial activity of the diarylheptanoids from the black and green alder. Rev Bras Bot 2015; 38: 441-446

20 Garg N, Manchanda G, Kumar A. Bacterial quorum sensing: circuits and applications. Antonie Van Leeuwenhoek 2014; 105: 289-305

21 Kimura $N$. Metagenomic approaches to understanding phylogenetic diversity in quorum sensing. Virulence 2014; 5: 433-442

22 Cooley M, Chhabra SR, Williams P. N-Acylhomoserine lactone-mediated quorum sensing: a twist in the tail and a blow for host immunity. Chem Biol 2008; 15: 1141-1147

23 Hartmann A, Schikora A. Quorum sensing of bacteria and trans-kingdom interactions of $\mathrm{N}$-acyl homoserine lactones with eukaryotes. J Chem Ecol 2012; 38: 704-713

24 Schuster M, Sexton DJ, Diggle SP, Greenberg EP. Acyl-homoserine lactone quorum sensing: from evolution to application. Annu Rev Microbiol 2013; 67: 43-63

25 Bjarnsholt T, Givskov M. The role of quorum sensing in the pathogenicity of the cunning aggressor Pseudomonas aeruginosa. Anal Bioanal Chem 2007; 387: 409-414

26 Hentzer M, Eberl L, Nielsen J, Givskov M. Quorum sensing: a novel target for the treatment of biofilm infections. BioDrugs 2003; 17: 241-250

27 Uroz S, Dessaux Y, Oger P. Quorum sensing and quorum quenching: the yin and yang of bacterial communication. Chembiochem 2009; 10: 205-216

28 Zhang LH, Dong $Y H$. Quorum sensing and signal interference: diverse implications. Mol Microbiol 2004; 53: 1563-1571 
29 Pejin B, Ciric A, Glamoclija J, Nikolic M, Sokovic M. In vitro anti-quorum sensing activity of phytol. Nat Prod Res 2015; 29: 374-377

30 Petrović J, Glamočlija J, Stojković D, Nikolić M, Ćirić A, Fernandes A, Ferreira IC, Soković M. Bioactive composition, antimicrobial activities and the influence of Agrocybe aegerita (Brig.) Sing on certain quorumsensing-regulated functions and biofilm formation by Pseudomonas aeruginosa. Food Funct 2014; 5: 3296-3303

31 Koh CL, Sam CK, Yin WF, Tan LY, Krishnan T, Chong YM, Chan KG. Plantderived natural products as sources of anti-quorum sensing compounds. Sensors (Basel) 2013; 13: 6217-6228

32 Yeo SSM, Tham FY. Anti-quorum sensing and antimicrobial activities of some traditional Chinese medicinal plants commonly used in SouthEast Asia. Malays J Microbiol 2012; 8: 11-20

33 Zaki AA, Shaaban MI, Hashish NE, El Sayed K, Amer MA, Lahloub MF, Khan IA. Anti-quorum sensing compound from Nerium oleander roots. Planta Med 2015; 81: PC11

34 Savoia D. New perspectives in the management of Pseudomonas aeruginosa infections. Future Microbiol 2014; 9: 917-928

35 Kim J, Hahn JS, Franklin MJ, Stewart PS, Yoon J. Tolerance of dormant and active cells in Pseudomonas aeruginosa PAO1 biofilm to antimicrobial agents. J Antimicrob Chemother 2009; 63: 129-141

36 Olejnickova K, Hola V, Ruzicka F. Catheter-related infections caused by Pseudomonas aeruginosa: virulence factors involved and their relationships. Pathog Dis 2014; 72: 87-94

37 McClean KH, Winson MK, Fish L, Taylor A, Chhabra SR, Camara M, Daykin M, Lamb JH, Swift S, Bycroft BW, Stewart GS, Williams P. Quorum sensing and Chromobacterium violaceum: exploitation of violacein production and inhibition for the detection of $\mathrm{N}$-acylhomoserine lactones. Microbiology 1997; 143: 3703-3711

38 Morohoshi T, Kato M, Fukamachi K, Kato N, Ikeda T. N-Acylhomoserine lactone regulates violacein production in Chromobacterium violaceum type strain ATCC 12472. FEMS Microbiol Lett 2008; 279: 124-130

39 Chu W, Vattem DA, Maitin V, Barnes MB, McLean RJ. Bioassays of quorum sensing compounds using Agrobacterium tumefaciens and Chromobacterium violaceum. Methods Mol Biol 2011; 692: 3-19

40 O'Toole GA, Kolter R. Initiation of biofilm formation in Pseudomonas fluorescens WCS365 proceeds via multiple, convergent signalling pathways: a genetic analysis. Mol Microbiol 1998; 28: 449-461

41 O'Toole GA, Kolter R. Flagellar and twitching motility are necessary for Pseudomonas aeruginosa biofilm development. Mol Microbiol 1998; 30: 295-304

42 Henrichsen J. Bacterial surface translocation: a survey and a classification. Bacteriol Rev 1972; 36: 478-503
43 Latifi A, Winson MK, Foglino M, Bycroft BW, Stewart GS, Lazdunski A, Williams P. Multiple homologues of LuxR and LuxI control expression of virulence determinants and secondary metabolites through quorum sensing in Pseudomonas aeruginosa PAO1. Mol Microbiol 1995; 17: 333-343

44 Rasmussen TB, Givskov M. Quorum sensing inhibitors: a bargain of effects. Microbiology 2006; 152: 895-904

45 Davies GD, Parsek MR, Pearson JP, Iglewski BH, Costerton JW, Greenberg EP. Involvement of cell-to-cell signals in the development of a bacterial biofilm. Science 1998; 280: 295-298

46 Mshvildadze V, Legault J, Lavoie S, Gauthier C, Pichette A. Anticancer diarylheptanoid glycosides from the inner bark of Betula papyrifera. Phytochemistry 2007; 68: 2531-2536

47 Lai YC, Chen CK, Lin WW, Lee SS. A comprehensive investigation of antiinflammatory diarylheptanoids from the leaves of Alnus formosana. Phytochemistry 2012; 73: 84-94

48 León-Gonzalez AJ, Acero N, Muñoz-Mingarro D, López-Lázaro M, MartínCordero $C$. Cytotoxic activity of hirsutanone, a diarylheptanoid isolated from Alnus glutinosa leaves. Phytomedicine 2014; 21: 866-870

49 Casey JT, O'Cleirigh C, Walsh PK, O'Shea DG. Development of a robust microtiter plate-based assay method for assessment of bioactivity. J Microbiol Methods 2004; 58: 327-334

50 Coffey BM, Anderson GG. Biofilm formation in the 96-well microtiter plate. In: Filloux A, Ramos JL, editors. Pseudomonas methods and protocols. New York: Humana Press; 2014: 631-643

51 Bertani I, Rampioni G, Leoni L, Venturi V. The Pseudomonas putida Lon protease is involved in $\mathrm{N}$-acyl homoserine lactone quorum sensing regulation. BMC Microbiol 2007; 7: 71

52 Massai F, Imperi F, Quattrucci S, Zennaro E, Visca P, Leoni L. A multitask biosensor for micro-volumetric detection of N-3-oxo-dodecanoylhomoserine lactone quorum sensing signal. Biosens Bioelectron 2011; 26: 3444-3449

53 Duan K, Surette MG. Environmental regulation of Pseudomonas aeruginosa PAO1 Las and Rhll quorum-sensing systems. J Bacteriol 2007; 189: 4827-4836

54 Fietcher MP, Diggle SP, Crusz SA, Chhabra SR, Camara M, Williams P. A dual biosensor for 2-alkyl-4-quinolone quorum-sensing signal molecules. Environ Microbiol 2007; 9: 2683-2693

55 Hansen MB, Nielsen SE, Berg K. Re-examination and further development of a precise and rapid dye method for measuring cell growth/cell kill. J Immunol Methods 1989; 119: 203-210 